\title{
On-Pump Versus Off-Pump Coronary Artery Bypass Surgery in High-Risk Patients
}

\author{
A Retrospective Propensity Score Matching Analysis
}

\author{
Qiang JI, ${ }^{1} \mathrm{MD}$, YunQing MeI, ${ }^{1} \mathrm{MD}$, Xisheng WANG,${ }^{1} \mathrm{MD}$, and Wenjun Ding, ${ }^{2} \mathrm{MD}$
}

\begin{abstract}
SUMMARY
This study aimed to evaluate on-pump versus off-pump coronary artery bypass grafting (CABG) in patients with a high-risk operative profile.

The pre-, intra- and post-operative data of high-risk patients with additive European system for cardiac operative risk evaluation (additive Euro-SCORE) over 6 undergoing isolated CABG from January 2008 to December 2011 in this center were investigated and retrospectively analyzed. Using the propensity score-matching method, those patients with similar pre- and intra-operative characteristics were selected and their early clinical outcomes were compared.

From January 2008 to December 2011, 485 consecutive patients (398 males, with a mean age of $70.9 \pm 9.0$ years) whose additive Euro-SCORE was over 6 were entered into this study. Off-pump coronary bypass grafting (OPCAB) was performed in $58.1 \%(n=282)$, and the remaining patients underwent conventional coronary artery bypass grafting (CCABG). After propensity score matching, the two groups of patients (90 OPCAB patients versus 90 CCABG patients) were similar with regard to pre- and intra-operative characteristics but not duration of surgical procedure. No significant differences in hospital mortality were found. Compared to CCABG, high-risk patients undergoing OPCAB had significantly lower prevalence of postoperative respiratory failure and postoperative renal failure $(6.7 \%$ versus $17.8 \%, P=$ $0.0386,5.6 \%$ versus $16.7 \%, P=0.0307$, respectively). Through multivariate logistic regression analysis, type of procedure (CCABG versus $\mathrm{OPCAB})$, as an independent risk factor, had an impact on the postoperative respiratory failure (OR $=2.36,95 \% \mathrm{CI} 1.44-4.97, P=0.0312)$ and postoperative renal failure $(\mathrm{OR}=2.86,95 \% \mathrm{CI} 1.61-5.81, P=0.0037)$.

Compared with CCABG, OPCAB reduced postoperative respiratory and renal morbidity in high-risk patients. (Int Heart J 2014; 55: 484-488)
\end{abstract}

Key words: Coronary artery bypass grafting, Cardiopulmonary bypass

$\mathrm{T}$ he efficacy of coronary artery bypass grafting $(\mathrm{CABG})$ has been well established in cardiac centers worldwide. CABG, as compared to medical therapy, not only improves quality of life, but also prolongs life in selected patient subsets. With the advances in surgical technology, the proportion of high-risk patients with an additive EuroSCORE over 6 undergoing CABG appears to be on the increase. ${ }^{1-4)}$

Conventional coronary artery bypass grafting (CCABG), using cardiopulmonary bypass (CPB) with cardioplegic arrest and aortic cross-clamp, has been the standard procedure for surgical revascularization. Off-pump coronary artery bypass grafting (OPCAB), avoiding the use of $\mathrm{CPB}$, has attracted the interest of an increasing number of surgeons and patients, and has assumed an increasing role in surgical practice. ${ }^{5)}$ A multicenter, prospective, randomized, parallel trial reported that OP$\mathrm{CAB}$ reduced early mortality and morbidity in high-risk pa- tients. ${ }^{6)}$ On the contrary, another randomized clinical trial demonstrated that mortality seemed higher after off-pump CABG; in addition, no significant difference in major adverse cardiac and cerebrovascular events was found between OP$\mathrm{CAB}$ and $\mathrm{CCABG}$ in patients with a high-risk operative profile. ${ }^{7}$ Whether OPCAB is better or not at reducing early mortality and postoperative morbidities in high-risk patients as compared to CCABG remains to be confirmed.

In this study, using the propensity score-matching method, we selected those high-risk patients with similar pre- and intra-operative characteristics and compared their early clinical outcomes, in order to evaluate the impact of OPCAB compared with $\mathrm{CCABG}$ on high-risk patients undergoing $\mathrm{CABG}$.

From the ${ }^{1}$ Departments of Thoracic Cardiovascular Surgery, Tongji Hospital of Tongji University and ${ }^{2}$ Department of Cardiovascular Surgery, Zhongshan Hospital of Fudan University, Shanghai, China.

Address for correspondence: YunQing Mei, MD, Department of Thoracic Cardiovascular Surgery of Tongji Hospital, Tongji University, Shanghai. 389 Xincun Rd., Shanghai, 200065, China. E-mail: bojidefeiying@sohu.com or Wenjun Ding, MD, Department of Cardiovascular Surgery of Zhongshan Hospital of Fudan University, Shanghai. 180 Fenglin Rd., Shanghai, 200032, China. E-mail: dwj12191@163.com.

Received for publication March 20, 2014. Revised and accepted May 5, 2014.

Released in advance online on J-STAGE October 7, 2014.

All rights reserved by the International Heart Journal Association. 


\section{METHODS}

Subjects: This study protocol was approved by the ethics committee of Tongji University and was consistent with the "Declaration of Helsinki".

From January 2008 to December 2011, all patients suffering from coronary artery disease undergoing isolated CABG in this center were investigated. The coronary anatomy of each patient, in association with the preoperative characteristics, was carefully evaluated for assignment to OPCAB or CCABG. In every patient complete anatomic revascularization of all diseased vessels with a luminal diameter greater than or equal to $1 \mathrm{~mm}$ was considered necessary. If the operating surgeon judged a complete revascularization feasible on the beating heart, OPCAB was scheduled. In patients in whom the location or the quality of the target vessels and the preoperative characteristics (for example, large left ventricle) was considered to make off-pump revascularization technically too challenging, $\mathrm{CCABG}$ was performed. All the procedures (either $\mathrm{OPCAB}$ or $\mathrm{CCABG}$ ) were performed by the same surgical team and there were no differences in the rate of adoption of OPCAB between the different surgeons. In this center, OP$\mathrm{CAB}$ had been performed routinely for $>5$ years before the launch of the trial, and all of the operations were performed by 3 surgeons highly experienced in both off-pump and on-pump surgery (each of the 3 participating surgeons performed at least $50 \%$ of their $\mathrm{CABG}$ procedures as OPCAB).

Patients with an additive Euro-SCORE over 6 were considered as high-risk patients. From January 2008 to December 2011, 930 consecutive patients suffering from coronary artery disease were admitted into this center and underwent isolated CABG. Of these 930 patients, 485 (398 males and 87 females, with a mean age of $70.9 \pm 9.0$ years) with an additive EuroSCORE over 6 were entered into this study. Among these 485 high-risk patients, $58.1 \%(n=282)$ received OPCAB, and the remaining patients (including 3 patients who had to be switched from off-pump to on-pump CABG due to various causes during surgery) underwent CCABG. The number of bypass conduits ranged from 2 to 5 (mean, 3.1 per patient). Left internal mammary artery was used as a bypass conduit in 452 patients $(93.2 \%)$, radial artery in 226 patients $(46.6 \%)$, and great saphenous vein graft in 312 patients $(64.3 \%)$. The pre-, intra- and post-operative data of all high-risk patients are shown in Table I. OPCAB had significantly lower prevalence of prior heart operation $(0.7 \%$ versus $4.4 \%, P=0.0102)$ as compared to $\mathrm{CCABG}$; the left ventricular ejection fraction (LVEF) measured by echo-Doppler in the OPCAB group was higher than that in the CCABG group $(0.48 \pm 0.11$ versus 0.46 $\pm 0.10, P=0.0408)$, but left ventricular end-diastolic diameter (LVEDD) in the OPCAB group was lower than that in the CCABG group (56 $\pm 8 \mathrm{~mm}$ versus $58 \pm 9 \mathrm{~mm}, P=0.0103)$; OPCAB surgery received a shorter operation time (208 \pm 30 minutes versus $241 \pm 51$ minutes, $P<0.0001)$ and a smaller number of grafts $(3.0 \pm 0.4$ versus $3.2 \pm 0.5, P<0.0001)$ compared with CCABG. The overall hospital mortality in this study was $2.3 \%$. The causes of death were as follows: low cardiac output $(n=6)$, pneumonia $(n=3)$, and arrhythmia $(n=2)$. As shown in Table I, hospital mortality in high-risk patients undergoing OPCAB was lower as compared to CCABG, but no significant difference was found $(P=0.2147)$. High-risk patients undergoing $\mathrm{OPCAB}$ as compared to $\mathrm{CCABG}$ had sig-
Table I. Characteristics of Patients Before Propensity Score-Matching

\begin{tabular}{|c|c|c|c|}
\hline & $\begin{array}{l}\text { OPCAB } \\
(n=282)\end{array}$ & $\begin{array}{l}\text { CCABG } \\
(n=203)\end{array}$ & $P$ \\
\hline \multicolumn{4}{|l|}{ Pre-operation } \\
\hline Age (years) & $71.0 \pm 8.8$ & $70.8 \pm 9.4$ & 0.8105 \\
\hline Gender (female) & 54 & 33 & 0.4720 \\
\hline BMI $\left(\mathrm{kg} / \mathrm{m}^{2}\right)$ & $25.1 \pm 3.8$ & $25.3 \pm 4.3$ & 0.5888 \\
\hline Recent smoking & 74 & 56 & 0.7561 \\
\hline COPD & 42 & 28 & 0.7940 \\
\hline Diabetes mellitus & 82 & 71 & 0.1978 \\
\hline Hypertension & 151 & 113 & 0.7117 \\
\hline Renal dysfunction & 22 & 9 & 0.1870 \\
\hline Prior CVA & 64 & 49 & 0.7444 \\
\hline Recent MI & 91 & 72 & 0.5596 \\
\hline Congestive heart failure & 147 & 110 & 0.7123 \\
\hline Prior heart operation & 2 & 9 & 0.0102 \\
\hline \multicolumn{4}{|l|}{ Extent of CAD } \\
\hline 2 vessel & 8 & 6 & 1.0000 \\
\hline 3 vessel & 274 & 197 & \\
\hline LM & 76 & 68 & 0.1312 \\
\hline LVEF & $0.48 \pm 0.11$ & $0.46 \pm 0.10$ & 0.0408 \\
\hline LVEDD (mm) & $56 \pm 8$ & $58 \pm 9$ & 0.0103 \\
\hline Euro-SCORE & $7.6 \pm 2.0$ & $7.9 \pm 2.3$ & 0.1267 \\
\hline \multicolumn{4}{|l|}{ Intra-operation } \\
\hline Urgent operation & 39 & 17 & 0.0832 \\
\hline Number of grafts & $3.0 \pm 0.4$ & $3.2 \pm 0.5$ & $<0.0001$ \\
\hline CPB time (minutes) & & $103.8 \pm 16.3$ & \\
\hline ACC time (minutes) & & $63.1 \pm 10.4$ & \\
\hline Operation time (minutes) & $208 \pm 30$ & $241 \pm 51$ & $<0.0001$ \\
\hline \multicolumn{4}{|l|}{ Post-operation } \\
\hline Peak inotropic score & $7.2 \pm 2.1$ & $8.4 \pm 2.3$ & $<0.0001$ \\
\hline LCOS & 18 & 21 & 0.1288 \\
\hline Use of IABP & 34 & 22 & 0.7737 \\
\hline Acute MI & 3 & 5 & 0.2883 \\
\hline Atrial fibrillation & 108 & 93 & 0.1122 \\
\hline Ventricular fibrillation & 2 & 3 & 0.6539 \\
\hline Intubation time (hours) & $16.8 \pm 3.8$ & $24.2 \pm 5.7$ & $<0.0001$ \\
\hline Respiratory failure & 25 & 37 & 0.0035 \\
\hline Pneumonia & 38 & 39 & 0.1017 \\
\hline Renal failure & 15 & 32 & 0.0002 \\
\hline Stroke & 5 & 7 & 0.2532 \\
\hline DSWI & 5 & 8 & 0.1630 \\
\hline Re-operation for bleeding & 3 & 8 & 0.0591 \\
\hline Blood transfusion & 99 & 131 & $<0.0001$ \\
\hline Length of ICU stay (days) & $2.1 \pm 0.7$ & $3.2 \pm 1.2$ & $<0.0001$ \\
\hline Length of hospital stay (days) & $10.5 \pm 2.5$ & $12.6 \pm 3.2$ & $<0.0001$ \\
\hline Hospital mortality & 4 & 7 & 0.2147 \\
\hline
\end{tabular}

OPCAB indicates off-pump coronary artery bypass grafting; CCABG, conventional coronary artery bypass grafting; BMI, body mass index; COPD, chronic obstructive pulmonary disease; CVA, cerebro-vascular accident; MI, myocardial infarction; CAD, coronary artery disease; LM, left main trunk disease; LVEF, left ventricular ejection fraction; LVEDD, left ventricular end-diastolic diameter; Euro-SCORE, European system for cardiac operative risk evaluation; $\mathrm{CPB}$, cardiopulmonary bypass; ACC, aortic cross clamping; LCOS, low cardiac output syndrome; IABP, intraaortic balloon pump; DSWI, deep sternal wound infection; and ICU, intensive care unit.

nificantly lower rates of postoperative respiratory failure $(P=$ $0.0035)$, postoperative renal failure $(P=0.0002)$, and blood transfusion $(P<0.0001)$, and had significantly shorter duration of mechanical ventilation and length of ICU stay as well as hospital stay (all $P<0.0001$ ).

Using the propensity score-matching method, those highrisk patients with similar pre- and intra-operative characteristics were selected, and their early clinical outcomes were com- 
pared. The primary endpoint was a composite of mortality and major complications comprising myocardial infarction, stroke, renal failure, respiratory failure, and reoperation for bleeding, occurring within 30 days following surgery.

Definition of postoperative morbidities and mortality: The first postoperative 24-hour quantitative measures of inotropes were evaluated by the inotropic score according to the following formula: $([$ dopamine + dobutamine $] \times 1)+($ milrinone $\times 15)+$ ([epinephrine + norepinephrine + isoprenaline $] \times 100) .{ }^{8)}$ Low cardiac output syndrome (LCOS) was defined as the need for inotropic support with vasoactive drugs or mechanical circulatory support with intra-aortic balloon to maintain systolic blood pressure greater than $90 \mathrm{mmHg}$ and the appearance of signs of impairment of body perfusion (cold extremities, hypotension, oliguria/anuria, lowered level of consciousness or a combination of these signs). Postoperative myocardial infarction was defined by either the appearance of new Q waves in 2 or more contiguous leads on the electrocardiogram, or an increase in the creatine kinase MB isoenzyme fraction of more than $50 \mathrm{U}$, in concert with an excess of $7 \%$ of the total creatinine kinase level. Postoperative pneumonia was defined as a positive result in a sputum culture requiring anti-infective treatment, or chest X-ray diagnosis of pneumonia following cardiac surgery. Postoperative respiratory failure was defined as duration of mechanical ventilation more than 48 hours or re-intubation following cardiac surgery. Postoperative renal failure was defined as an increased plasma creatinine $\times 2$ associated with urine production less than $0.5 \mathrm{~mL} / \mathrm{kg} /$ hour $\times 12$ hours. Postoperative stroke was defined as a permanent neurologic deficit that persisted either at the time of hospital discharge or until death. Reoperation for bleeding was defined as the need for chest reopening in the presence of more than $500 \mathrm{~mL}$ of blood from chest tubes within the first hour, more than $400 \mathrm{~mL}$ within the second hour, more than $300 \mathrm{~mL}$ within the third hour, or total bleeding greater than $1000 \mathrm{~mL}$ within the fourth hour. Hospital mortality was defined as death that occurred during the same hospitalization or within 30 days of operation. In addition, deep sternal wound infection (bone-related; any drainage of purulent material from the sternotomy wound, and instability of the sternum) and blood transfusion were recorded. Surgical procedure: For those patients who underwent CCA$\mathrm{BG}, \mathrm{CPB}$ was instituted with a single two-stage right atrial cannulation and an ascending aorta perfusion cannulation. Standard management included membrane oxygenators, arterial catheter filters, and non-pulsatile flow of $2.4 \mathrm{~L} / \mathrm{minute} / \mathrm{m}^{2}$, with a mean arterial blood pressure greater than $50 \mathrm{mmHg}$. Patients were heparinized with $3 \mathrm{mg} / \mathrm{kg}$ to achieve an activated clotting time $>480$ seconds. Heparin was neutralized with 1 $\mathrm{mg}$ protamine sulfate per $1 \mathrm{mg}$ given. Moderate hemodilution (hematocrit, $20 \%$ to $25 \%$ ) was used during CPB. The patients were routinely cooled to $32^{\circ} \mathrm{C}$ for grafting. Cold-blood cardioplegia was accomplished with anterograde delivery through the aortic root and retrograde delivery through the coronary sinus. All anastomoses were sutured by hand.

OPCAB procedures were performed through a median sternotomy. Patients were heparinized with $1 \mathrm{mg} / \mathrm{kg}$ intravenously to achieve activated clotting time $>300$ seconds. The central temperature, which was measured by a pulmonary artery catheter, was maintained above $36^{\circ} \mathrm{C}$ using a warm mattress, a forced warm air blanket, and a fluid warmer where necessary. The heart was displaced using a posterior pericar- dial stitch, large $(12 \times 70 \mathrm{~cm})$ gauze swabs and a tissue stabilizer (Octopus, Medtronic Corporation, Minneapolis, MN). Body position changes and gravity support (Trendelenburg, right and left table rotations), in combination with the administration of vasoactive agents (for example, norepinephrine), were carried out to stabilize hemodynamics during OPCAB. A $\mathrm{CO}_{2}$-blower/ $\mathrm{NaCl}$ mister device was used in situations where a bloodless field was not achieved with proximal target vessel occlusion. An intra-coronary shunt (Medtronic Corporation, Minneapolis, MN) was used during grafting. Blood loss was collected in a cell salvage device, and the salvaged blood was re-infused into the patient before the completion of surgery. The sequence of grafting was always from the left internal mammary artery to the left anterior descending coronary artery first, followed by grafting of the circumflex coronary artery and right coronary artery using a radial artery or saphenous vein. Before proximal anastomosis of grafts was performed, ascending aortic sclerosis or calcification was assessed based on the following parameters: preoperative imaging examination, including X-rays as well as echocardiography, and intraoperative palpation and transesophageal echocardiography. "No-touch" aorta technique or eNclose (Novare Surgical Systems Inc., American) was available when moderate to severe sclerosis or calcification was detected.

The quality of anastomosis was assessed after grafting with the use of a transit-time flow probe (Medistim Butterfly Flow Meter, Oslo, Norway) in all patients. All patients were transferred to the intensive care unit following surgery.

Statistical analysis: Statistical analysis was performed using the SPSS13.0 statistical software package (SPSS, Inc., Chicago, IL). All $P$ values $<0.05$ were considered indicative of statistical significance. The data are expressed as the mean and $\mathrm{SD}$. Univariate analysis, using the unpaired $t$-test to compare measurement data and Fisher's exact test to compare enumeration data, was performed to assess statistically significant variables. Stepwise multivariate logistic regression was also performed to assess the impact of type of procedure (CCABG versus $\mathrm{OPCAB}$ ) as an independent risk factor on mortality and major postoperative morbidities in high-risk patients.

\section{RESUlts}

After the propensity score-matching, 180 high-risk patients (90 patients in the OPCAB group and 90 patients in the CCABG group) were included and analyzed. The pre-, intraand post-operative data of these 180 high-risk patients are shown in Table II. The two groups of patients were similar with regard to pre- and intra-operative characteristics but not duration of surgical procedure. As shown in Table II, high-risk patients undergoing $\mathrm{OPCAB}$ as compared to CCABG had significantly lower rates of postoperative respiratory failure $(6.7 \%$ versus $17.8 \%, P=0.0386)$, postoperative renal failure $(5.6 \%$ versus $16.7 \%, P=0.0307$ ), and blood transfusion ( $31.1 \%$ versus $60.0 \%, P=0.0002)$, and had significantly shorter duration of mechanical ventilation (17.6 \pm 3.5 hours versus $23.8 \pm 4.9$ hours, $P<0.0001)$ and length of ICU stay as well as hospital stay $(2.3 \pm 0.8$ days versus $3.1 \pm 1.1$ days, $P<0.0001,11.2 \pm$ 2.3 days versus $12.5 \pm 3.1$ days, $P<0.0001$, respectively). No significant differences in hospital mortality and major adverse cardiac-cerebrovascular events were found between OPCAB 
Table II. Peri-Operative Data in High-Risk Patients Undergoing CABG After Propensity Score-Matching

\begin{tabular}{|c|c|c|c|}
\hline & $\begin{array}{l}\text { OPCAB } \\
(n=90)\end{array}$ & $\begin{array}{l}\text { CCABG } \\
(n=90)\end{array}$ & $P$ \\
\hline \multicolumn{4}{|l|}{ Pre-operation } \\
\hline Age (years) & $72.3 \pm 5.8$ & $72.1 \pm 5.2$ & 0.8078 \\
\hline Gender (female) & 16 & 14 & 0.8418 \\
\hline BMI $\left(\mathrm{kg} / \mathrm{m}^{2}\right)$ & $25.1 \pm 2.8$ & $25.2 \pm 2.5$ & 0.8001 \\
\hline Recent smoking & 24 & 27 & 0.6230 \\
\hline COPD & 18 & 14 & 0.6416 \\
\hline Diabetes mellitus & 28 & 36 & 0.2155 \\
\hline Hypertension & 47 & 51 & 0.5516 \\
\hline Renal dysfunction & 7 & 3 & 0.3296 \\
\hline Prior CVA & 34 & 30 & 0.6406 \\
\hline Recent MI & 47 & 41 & 0.4560 \\
\hline Congestive heart failure & 45 & 50 & 0.5505 \\
\hline Prior heart operation & 1 & 1 & 1.0000 \\
\hline \multicolumn{4}{|l|}{ Extent of CAD } \\
\hline 2 vessel & 2 & 3 & 1.0000 \\
\hline 3 vessel & 88 & 87 & \\
\hline LM & 33 & 30 & 0.7548 \\
\hline LVEF & $0.46 \pm 0.09$ & $0.45 \pm 0.07$ & 0.4053 \\
\hline LVEDD (mm) & $56 \pm 8$ & $57 \pm 8$ & 0.4014 \\
\hline Euro-SCORE & $7.7 \pm 2.1$ & $7.6 \pm 2.2$ & 0.7546 \\
\hline \multicolumn{4}{|l|}{ Intra-operation } \\
\hline Urgent operation & 16 & 8 & 0.1235 \\
\hline Number of grafts & $3.0 \pm 0.4$ & $3.1 \pm 0.5$ & 0.1386 \\
\hline CPB time (minutes) & & $105.4 \pm 16.6$ & \\
\hline ACC time (minutes) & & $64.2 \pm 10.3$ & \\
\hline Operation time (minutes) & $211 \pm 32$ & $238 \pm 48$ & $<0.0001$ \\
\hline \multicolumn{4}{|l|}{ Post-operation } \\
\hline Peak inotropic score & $7.3 \pm 2.1$ & $7.9 \pm 2.5$ & 0.0817 \\
\hline LCOS & 5 & 7 & 0.7665 \\
\hline Use of IABP & 11 & 7 & 0.5534 \\
\hline Acute MI & 1 & 2 & 1.0000 \\
\hline Atrial fibrillation & 24 & 29 & 0.5133 \\
\hline Ventricular fibrillation & 0 & 1 & 1.0000 \\
\hline Intubation time (hours) & $17.6 \pm 3.5$ & $23.8 \pm 4.9$ & $<0.0001$ \\
\hline Respiratory failure & 6 & 16 & 0.0386 \\
\hline Pneumonia & 12 & 18 & 0.3174 \\
\hline Renal failure & 5 & 15 & 0.0307 \\
\hline Stroke & 1 & 3 & 0.6208 \\
\hline DSWI & 1 & 3 & 0.6208 \\
\hline Re-operation for bleeding & 1 & 2 & 1.0000 \\
\hline Blood transfusion & 28 & 54 & 0.0002 \\
\hline Length of ICU stay (days) & $2.3 \pm 0.8$ & $3.1 \pm 1.1$ & $<0.0001$ \\
\hline Length of hospital stay (days) & $11.2 \pm 2.3$ & $12.5 \pm 3.1$ & 0.0018 \\
\hline Hospital mortality & 1 & 3 & 0.6208 \\
\hline
\end{tabular}

Abbreviations are the same as in Table I.

and CCABG in patients with a high-risk operative profile.

Those variables (hospital mortality and major postoperative morbidities) entered into a stepwise multivariate logistic regression to assess the impact of type of procedure (CCABG versus $\mathrm{OPCAB}$ ) as an independent risk factor on mortality and major postoperative morbidities in high-risk patients. Through multivariate logistic regression analysis, type of procedure (CCABG versus OPCAB), as an independent risk factor, had an impact on postoperative respiratory failure $(\mathrm{OR}=2.36$, 95\% CI 1.44-4.97, $P=0.0312$ ) and postoperative renal failure $(\mathrm{OR}=2.86,95 \% \mathrm{CI} 1.61-5.81, P=0.0037)$.

\section{Discussion}

Coronary patients tend to be older and more ill, with a high frailty index, a high predicted risk of mortality, and complex 3-vessel coronary artery disease. This picture is peculiar to the group of patients requiring surgical treatment and who will be a part of the practice of cardiac surgeons in the coming years. Compared with low-risk patients, high-risk patients faced much greater operative risk. ${ }^{9)}$ Avoiding organ damage caused by cardiopulmonary bypass and hypothermia, and reducing systemic inflammation response and blood component damage, OPCAB may be a more profitable choice for those patients with coronary artery disease undergoing $\mathrm{CABG}$ as compared to $\mathrm{CCABG}$, especially for high-risk patients. In the United States, there is already a national trend that favors OP$\mathrm{CAB}$ for elderly and frail patients, in the belief that cardiopulmonary bypass could be dangerous for them. ${ }^{10)}$ This trend is based on the results from several retrospective analyses of large databases that have clearly shown reduced risk-adjusted mortality after OPCAB compared with after CCABG. ${ }^{11,12)}$ The on-off study showed that OPCAB was safer than CCABG at 30 days for high-risk patients. In that study, the primary composite endpoint (operative mortality, MI, neurologic complications, renal failure, and reoperation for bleeding) favored OP$\mathrm{CAB}$ compared with $\mathrm{CCABG}$ in the intention-to-treat analysis. However, another randomized clinical trial demonstrated that mortality seemed higher after off-pump CABG; in addition, no significant difference in major adverse cardiac and cerebrovascular events was found between OPCAB and CCABG in patients with a high-risk operative profile. ${ }^{7)}$ Therefore, whether OPCAB was more favorable to reduce early mortality and postoperative morbidities in high-risk patients as compared to $\mathrm{CCABG}$ or not remains to be confirmed.

In this study, we compared OPCAB with CCABG in a retrospective propensity score matching analysis with 180 patients. We found no significant difference in the prevalence of hospital mortality, postoperative acute myocardial infarction, postoperative new onset of atrial and ventricular fibrillation, nonfatal stroke, postoperative pneumonia, deep sternal wound infection, or re-operation for bleeding within 30 days of surgery. However, among patients undergoing OPCAB, we found reductions in numerous secondary outcomes, including the prevalence of transfusion of blood products, renal failure, respiratory failure, and duration of mechanic ventilation and ICU stay as well as hospital stay. In this study, high-risk patients undergoing OPCAB compared with CCABG had significantly lower incidences of postoperative respiratory and renal failure, showing that OPCAB surgery preserved pulmonary and renal function. Better pulmonary as well as renal protection, in association with reduction of quantity of drainage as well as blood transfusion, may contribute to shorter length of ICU stay as well as hospital stay, and hence may be conducive to postoperative recovery in high-risk patients undergoing OPCAB compared with CCABG.

Louagie and associates performed a retrospective casematched study of $90 \mathrm{CCABG}$ and OPCAB patients, with respect to age, sex, body surface area, number of diseased vessels, and LVEF. ${ }^{13)}$ They found no difference in the prevalence of postoperative atrial fibrillation or reoperation for bleeding. Although OPCAB patients experienced a shorter ICU stay than did CCABG patients, hospital stay was nearly equivalent. 
This evidence was in line with our study about postoperative atrial fibrillation, reoperation for bleeding, and length of ICU stay but was different from hospitalization stay. A study conducted by Lemma on CABG in high-risk patients indicated that mortality, myocardial infarction, stroke, and renal failure following $\mathrm{OPCAB}$ are lower than CCABG surgery. ${ }^{6}$ This evidence was in line with our study about postoperative renal failure but was different from postoperative mortality and major postoperative morbidity, such as myocardial infarction and stroke. The reason for this difference can be the limited sample size, since our study only included $90 \mathrm{CCABG}$ and $90 \mathrm{OP}-$ $\mathrm{CAB}$ patients. Another big study on $\mathrm{CCABG}$ versus $\mathrm{OPCAB}$ by $\mathrm{Chu}$ reported that $\mathrm{OPCAB}$ did not reduce postoperative mortality or stroke rates compared to CCABG. ${ }^{14)}$ Furthermore, longer ICU and hospital stays following OPCAB were observed in that study. This evidence was in line with our study about mortality after surgery but was different from ICU and hospitalization stays. The reason for this difference can be the type of patients since that our study focused on high risk patients. Another randomized clinical trial conducted by Moller on $\mathrm{CABG}$ in high-risk patients with three-vessel disease demonstrated that mortality seemed higher after off-pump CABG; in addition, no significant difference in major adverse cardiac and cerebrovascular events was found between OPCAB and CCABG in patients with a high-risk operative profile. ${ }^{7)}$ This evidence was just the reverse of our study and some studies mentioned above. Therefore, prospective multicenter clinical trials involving larger sample sizes are needed to determine the clinical effect of OPCAB in high-risk patients compared to CCABG

There are some limitations of this study. It was only a retrospective clinical observational trial in a single center, which may influence the generalizability. We cannot exclude the possibility that our results are under the influence of some degree of performance bias because surgeons had to remain unblinded and because we chose to inform patients about the treatment allocation. Three patients scheduled to undergo OPCAB had to be switched to CCABG due to unstable hemodynamics or malignant ventricular arrhythmia during surgery, and were included in the CCABG analysis. As these were 'unstable' patients, it added considerable bias. Finally, this study only evaluated the early impact (within 30 days following surgery) of OPCAB compared with $\mathrm{CCABG}$ on high-risk patients by measuring the clinical outcomes after CABG.

In conclusion, this study showed that $\mathrm{CCABG}$ and OPCABG patients with a high-risk operative profile matched with respect to risk factors experienced a similar prevalence of selected complications although some clinical results were better with off-pump technique. Compared with $\mathrm{CCABG}, \mathrm{OPCAB}$ reduced postoperative respiratory and renal morbidity, and shortened ICU and hospital stay in high-risk patients. So, OP$\mathrm{CABG}$ is recommended as an alternative surgical modality treatment for CCABG in coronary disease patients with a highrisk operative profile.

\section{REFERENCES}

1. Kurlansky P. Do octogenarians benefit from coronary artery bypass surgery: a question with a rapidly changing answer? Curr Opin Cardiol 2012; 27: 611-9. (Review)

2. Nicolini F, Molardi A, Verdichizzo D, et al. Coronary artery surgery in octogenarians: evolving strategies for the improvement in early and late results. Heart Vessels 2012; 27: 559-67.

3. Biancari F, Vasques F, Mikkola R, Martin M, Lahtinen J, Heikkinen J. Validation of EuroSCORE II in patients undergoing coronary artery bypass surgery. Ann Thorac Surg 2012; 93: 1930-5.

4. Cornwell LD, Chu D, Misselbeck T, et al. Predicting mortality in high-risk coronary artery bypass: surgeon versus risk model. J Surg Res 2012; 174: 185-91.

5. Godinho AS, Alves AS, Pereira AJ, Pereira TS. On-pump versus off-pump coronary-artery bypass surgery: a meta-analysis. Arq Bras Cardiol 2012; 98: 87-94. (Review) (English, Portuguese, Spanish)

6. Lemma MG, Coscioni E, Tritto FP, et al. On-pump versus offpump coronary artery bypass surgery in high-risk patients: operative results of a prospective randomized trial (on-off study). J Thorac Cardiovasc Surg 2012; 143: 625-31.

7. Møller CH, Perko MJ, Lund JT, et al. Three-year follow-up in a subset of high-risk patients randomly assigned to off-pump versus on-pump coronary artery bypass surgery: the Best Bypass Surgery trial. Heart 2011; 97: 907-13.

8. Ji Q, Mei Y, Wang X, et al. Combination of irbesartan and amiodarone to maintain sinus rhythm in patients with persistent atrial fibrillation after rheumatic valve replacement. Circ J 2010; 74: 1873-9.

9. Goto M, Kohsaka S, Lee VV, Elayda MA, Aoki N, Wilson JM. Risk stratification of coronary revascularization patients by using clinical and angiographic data. J Cardiovasc Surg (Torino) 2011; 52: 863-71.

10. Puskas JD, Edwards FH, Pappas PA, et al. Off-pump techniques benefit men and women and narrow the disparity in mortality after coronary bypass grafting. Ann Thorac Surg 2007; 84: 1447-54.

11. Plomondon ME, Cleveland JC, Ludwig ST, et al. Off-pump coronary artery bypass is associated with improved risk-adjusted outcomes. Ann Thorac Surg 2001; 72: 114-9.

12. Puskas JD, Thourani VH, Kilgo P, et al. Off-pump coronary artery bypass disproportionately benefits high-risk patients. Ann Thorac Surg 2009; 88: 1142-7.

13. Louagie Y, Jamart J, Broka S, Collard E, Scavée V, Gonzalez M. Off-pump coronary artery bypass grafting: a case-matched comparison of hemodynamic outcome. Eur J Cardiothorac Surg 2002; 22: $552-8$.

14. Chu D, Bakaeen FG, Dao TK, Lemaire SA, Coselli JS, Huh J. Onpump versus off-pump coronary artery bypass grafting in a cohort of 63,000 patients. Ann Thorac Surg 2009; 87: 1820-6. 